Carlayne E. Jackson, M.D.

Richard J. Barohn, M.D.

\title{
A RANDOMIZED CLINICAL TRIAL OF THYMECTOMY FOR THE TREATMENT OF MYASTHENIA GRAVIS
}

\section{Specific Aims:}

A. To determine whether thymectomy added to best medical management has an effect on the rate of complete remission in patients with myasthenia gravis (MG) in a randomized, prospective study.

B. To determine whether thymectomy added to best medical management has an effect on the rate of pharmacologic remission or on clinical improvement in patients with MG in a randomized, prospective study.

C. To determine whether there are specific subsets of MG patients such as age, sex, acetylcholine receptor antibody titer, or severity of disease which predict a better response to thymectomy.

\section{Background and Significance:}

In 1939, Blalock (1) reported the remission of generalized MG in a $21 \mathrm{y} / \mathrm{o}$ women following removal of the cystic remains of a necrotic thymic tumor. Since then thymectomy, with or without the presence of thymoma, has gained widespread acceptance as a form of treatment for MG. Thus, thymectomy was the first attempt at "immunotherapy" for MG and continues to be one of the most frequently utilized attempts at treatment. However, all studies on the possible effectiveness of thymectomy are based on retrospective or case control studies. A randomized study has yet to be done despite calls for such a trial by experts in the neuromuscular community (2). Since medical management of MG and respiratory intensive care has now so dramatically shifted the curve of morbidity and mortality, it would seem more necessary than ever to re-examine the potential benefit of thymectomy in a scientifically sound manner.

The role of the thymus gland in the pathogenesis of myasthenia gravis remains highly controversial. Up to $80 \%$ of patients with MG have thymus abnormalities, with $10-15 \%$ being thymus tumors and the remainder consisting of lymphoid hyperplasia (3). Lymphocytes in the thymus and peripheral blood appear to be sensitized to muscle in MG patients, and recent evidence indicates that thymus tissue from MG patients with and without thymoma are enriched in AchR-reactive T cells (4). On the other hand, Tindall (5) reported that thymectomy resulted in either no early change in acetylcholine receptor antibody levels or a slow and gradual fall requiring a much longer follow-up. Similar results were reported by Kornfeld et al (6) and Roses et al (7).

In experimental autoimmune myasthenia gravis (EAMG) it is the chronic phase that most closely resembles the human disease (8), yet neither thymectomy nor early treatment with antithymocyte serum alters this phase of EAMG (9). Thymectomy in EAMG has not been shown to have any effect on circulating lymphocyte subpopulations (10).

The problems that exist in analyzing prior retrospective studies on the efficacy of thymectomy have been well identified (11). One difficulty is that a determination of the status of remission and improvement by a retrospective unblinded chart analysis is potentially fraught with error. In addition, while most authors agree that "remission" refers to a patient who is asymptomatic off no medications, the category of "improvement" is very subjective and arbitrary. Some authors have defined 
improvement to be a mean reduction in the dosage of anticholinesterase medication $(12,13,14)$. These studies relied frequently on quality of life questionnaires rather than on actual neurologic examinations. Indeed, identifying patients who are in remission in a prospective study will be challenging, as outlined below.

McQuillen and Leone (11) compared the remission rates between patients receiving medical and surgical management reported in several large series performed, with one exception, prior to 1965 . This date was chosen because treatment with corticosteroids for myasthenia gravis began the following year. They could find no significant differences between the two treatment groups. Abstracted is the key

information from their review:

\begin{tabular}{|c|c|c|}
\hline \multicolumn{3}{|c|}{ REMISSION RATE: NONSURGICAL } \\
THERAPY \\
\hline Author & $n$ & Percent \\
\hline Kennedy and Moersch (17) & 87 & 31 \\
\hline Grob (18) & 202 & 23 \\
\hline Simpson (12) & 99 & 16 \\
\hline Oosterhuis (19) & 180 & 31 \\
\hline Perlo and associates (15) & 417 & 24 \\
\hline OVERALL & 985 & 24 \\
\hline
\end{tabular}

\begin{tabular}{|c|c|c|}
\hline \multicolumn{3}{|c|}{ REMISSION RATE: SURGICAL THERAPY } \\
\hline Author & $\boldsymbol{n}$ & Percent \\
\hline Simpson (12) & 258 & 21 \\
\hline Perlo and associates (15) & 267 & 34 \\
\hline Mulder and associates (13) & 73 & 36 \\
\hline Emeryk and Strugalska (14) & 112 & 23 \\
\hline $\begin{array}{c}\text { Patatestas and associates } \\
\text { (16) }\end{array}$ & 111 & 25 \\
\hline OVERALL & 821 & 28 \\
\hline \hline
\end{tabular}

Considering that this early era in the treatment of MG would bias the results against medical therapy, it is even more impressive that there seems to be little difference.

Other methodologic problems with these early studies include treatment groups that were not comparable in terms of age, sex, or severity of disease. When these variables were considered, some authors showed that remission rates did not appear to depend on age (20), although others observed a much greater benefit in those younger than $40(12,21)$. Women reportedly have a $14-23 \%$ better benefit from thymectomy; yet several series did not show a difference in benefit between sexes $(12,14,15,22)$. In some reports, there is a suggestion that the more severe the MG grade before thymectomy, the more likely the patient is to improve (15); other series report the opposite (13) while some were unable to show any significant difference between groups based on disease severity $(14,21)$. One of the largest retrospective studies published was that of Perlo (15) who reported the results of 267 patients. Complete remission post-thymectomy occurred in $35 \%$, with an additional $41 \%$ showing improvement defined as the control of symptoms on medications. However, the response to thymectomy was not immediate. Of the 92 patients that ultimately achieved a complete remission over a 10 year period, only $25 \%$ remitted the first year, $40 \%$ the second year and $55 \%$ in three years. Complete remission in the medical group was only $17 \%$ with an additional $11 \%$ showing improvement. 
A more recent retrospective report by Fujii et al (23) also enthusiastically endorses thymectomy. In this retrospective study, the authors examined the course of 50 patients who underwent transternal thymectomy and showed a $32 \%$ complete remission rate and concluded that preoperative clinical stage, duration of disease and serum acetylcholine receptor antibody titer did not affect the post-operative prognosis. However, they also suggested that women and patients $<40$ years of age showed more benefit than other patients. The authors were also able to demonstrate significant increases in CD3+ cells, HLADR + cells and B cells in the thymus of patients who had a poor post-operative course. On the other hand, Beghi et al (21) retrospectively analyzed the courses of 844 patients, of whom $63 \%$ had thymectomy, and found that thymectomized subjects had only a slightly increased chance of complete remission compared to non-surgical patients, and this was considered to be of borderline significance. They felt that younger age and shorter duration of disease may have contributed to an increased likelihood of remission. However, they recommended that a prospective randomized study be performed to resolve these issues.

The controversy surrounding thymectomy will undoubtedly continue until a proper randomized, clinical trial is performed in a population homogeneous for variables presumed to be predictive of response, i.e., age, sex, and severity of disease. A randomized trial to clearly define the role of thymectomy is long overdue due to the invasive nature of this procedure.

\section{Experimental design and methods:}

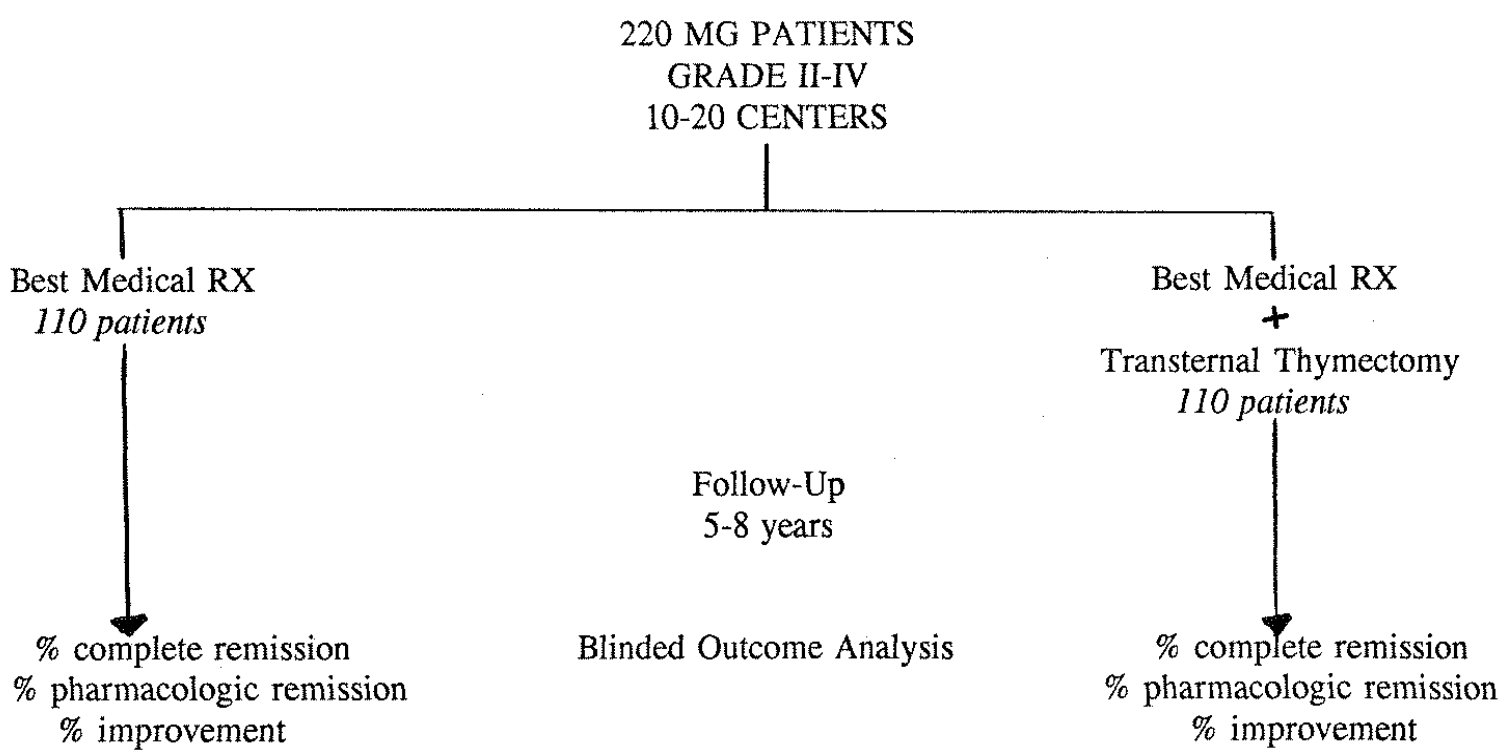

A. Diagnosis: All patients admitted to the study must have a diagnosis of MG. The diagnosis of MG will be made by the unblinded clinical investigators at each facility. The diagnosis will be based on:

1) An elevated acetylcholine receptor antibody

2) Ocular, facial, bulbar, or extremity weakness and fatigability without other neurologic etiology.

Other supportive evidence for myasthenia gravis includes a positive Tensilon test and abnormal repetitive stimulation or single-fiber EMG, but these are not mandatory for the study. 
B. Classification: All MG patients will be classified according to the severity of their disease using a modified Osserman classification that was developed and currently is used at the University of Texas Health Science Center of San Antonio. The classification is as follows:

Grade 1: Ocular involvement alone (ptosis, diplopia, orbicularis oculi weakness in the absence of other bulbar, neck or limb weakness is allowable in this group).

Grade 2: Mild generalized MG; normal activities of daily living are preserved with only mild symptoms of weakness or fatiguability. Includes patients with subjective complaints of only ocular weakness but who on exam show evidence of limb/neck weakness. Symptoms necessitate initiation of treatment with Mestinon therapy alone (no immunosuppressive drugs needed).

Grade 2b: Mild restricted MG; normal activities of daily living are preserved with only mild weakness restricted to bulbar involvement without subjective limb weakness(may have subjective/objective neck weakness; the only allowable objective limb weakness would be of the hip flexors, which can be no worse than MRC grade 4; may also have ocular involvement). Symptoms necessitate treatment with Mestinon therapy alone (no immunosuppressive drugs needed).

Grade 3: Moderate generalized MG; normal activities of daily living are interrupted because of weakness and fatigue. Symptoms require initiation of treatment with immunosuppressive therapy.

Grade 3b: Moderate restricted MG; restricted to bulbar and /or respiratory (diaphragmatic) involvement without subjective limb weakness (may have subjective/objective neck weakness; the only allowable objective limb weakness would be of the hip flexors, which can be no worse than MRC grade 4; may also have ocular involvement); no impending respiratory failure or inability to swallow requiring mechanical feeding. Immunosuppressive therapy is required for treatment.

Grade 4: Severe generalized MG (myasthenic crisis); profound weakness in the extremities requiring confinement to bed and hospitalization; established respiratory failure requiring mechanical ventilation or bulbar weakness requiring mechanical feeding.

Grade 4b: Severe restricted MG (myasthenic crisis); restricted to bulbar and/or respiratory muscles with no subjective limb weakness (may have neck weakness and hip flexor weakness on exam no worse than MRC grade 4; may have ocular involvement); requires mechanical feeding or mechanical ventilation.

Grade 0 (remission): This stage will not be used at the time of entry into the study, but will be used at follow-up evaluations. Patients in clinical remission can include the following groups.

Grade 0a: No objective cranial nerve or extremity weakness. Off all medications.

Grade 0b: No objective cranial nerve or extremity weakness. Remains on Mestinon. 
Grade 0c: No objective cranial nerve or extremity weakness. Remains on immunosuppressive drugs.

Grade $0 a+, 0 b+, 0 c+$ : Any of the above 0 grades, but the patient may still have slight orbicularis oculi or hip flexor weakness (grade $4+$ or 5-), despite the absence of any subjective symptoms of ocular/bulbar or extremity weakness.

C. Inclusion Criteria: Patient selection will be based on a clinical diagnosis of myasthenia gravis, with all of the following specific criteria:

1) Patients between the ages of 18 and 50 who demonstrate evidence of ocular, facial, bulbar, or extremity weakness based on neurologic examination and history. Entry must be within 6 months of initial diagnosis. Ocular weakness alone will not be acceptable for the purposes of this study (ie. patients must be grade 2-4). Patients with grade 1 disease will be followed monthly, and should generalized symptoms or signs develop, they can then be randomized. Patients must be entered within 6 months of onset of generalized symptoms. Patients will not be excluded if standard medical therapy has already been initiated ( Mestinon, prednisone, Imuran, IVIG, plasmapheresis).

2). A definite diagnosis of MG must be accompanied by the presence of an elevated acetylcholine receptor antibody titer.

3) The patient's signs and symptoms should not be able to be better explained by some other disease process.

4) Patients must be physically healthy for their age and diagnosis without a history of another major chronic or debilitating illness.

5) Patients must be properly motivated, willing to cooperate in not unbinding the study, and willing to return for the follow-up visits during the study.

6) Patients must give written informed consent before participating in this study. A copy of the witnessed consent must be noted in the Investigator's medical records.

\section{Exclusion Criteria:}

1) Patients who cannot undergo thymectomy due to other medical conditions.

2) Patients suspected of having a thymus tumor based upon abnormal chest CT or MRI.

3) Patients with altered levels of consciousness, dementia, or abnormal mental status.

4) Patients with a history of neurologic, chronic degenerative or psychiatric disorders other than MG.

5) Females who are pregnant or lactating.

E. Study Entry/Randomization: At the initial presentation of the patient, the investigator at each center will perform a clinical evaluation which will determine the patient's eligibility for participation in the study. All patients will undergo the following studies prior to enrollment: 1) acetylcholine receptor antibody level, 2) chest CT or MRI. Patients who do not meet the inclusion criteria or who have exclusion criteria will not be entered into the study.

For those patients who do meet the criteria, the investigator will perform a baseline evaluation which will include: manual muscle testing of 34 muscle groups using a MRC (25) scale (Appendix A), hand grip strength (in $\mathrm{kg}$ ) using a Jamar dynamometer, forced vital capacity (in liters) using a pulmonary function monitor, a battery of quantitative functional tasks (Appendix B) and a questionnaire indicating the patient's level of disability in terms of activities of daily living (ADLs) (Appendix C). Protocol eligibility and admission information consisting of demographic data, 
summary of history, examination findings, and results of diagnostic studies on each patient will be entered into patient booklets and the data forwarded to the Project Clinical Coordinator promptly after patient enrollment (Appendix D).

All patients will then be randomized to the following treatment groups:

1) Medical treatment alone

2) Thymectomy: patients in the thymectomy group may also be placed on medical therapy as necessitated by the severity of the disease. All thymectomies should be done through a trans-sternal surgical approach. Thymectomies will be done within 6 weeks of randomization.

Registration and randomization will be performed through the Patient Registration Office at the University of Texas Health Science Center in San Antonio by calling (210)567-4750 during the hours of 9AM to 4PM Central time, Monday through Friday. Since this is a multi-center trial, randomization will be accomplished using dynamic allocation to ensure that the number of patients are balanced over centers with regards to treatment group, age $(<40$ versus $>40)$, and grade of disease (grade 2 versus grade 3).

F. Follow-up and Data Collection: Patients will be entered over a three year period, and the study will be continued until all patients have been followed at least 5 years. Patients will have follow-up examinations by a physician who will not have prior knowledge with regard to whether or not the patient had a thymectomy, i.e., the "Blinded Investigator" (BI). The BI will be a co-investigator from the nearest study center who will travel to the same study center every 6 months. The first follow-up evaluation will be performed within 6 months after randomization and then at 6 month intervals. Training sessions for all of the participating BI's will be required to ensure consistency with performing the testing outlined below and filling out the case report forms. During these BI evaluations, patients will be required to wear turtlenecks or shirts buttoned at the collar in order to conceal any surgical scars and will be reminded not to offer any information which could potentially unblind the study. The BI will not have access to the patient's clinic or hospital records nor to the results of the patient's prior study evaluations.

The BI will be responsible for completing the following battery of testing:

1. Manual Muscle Testing

2. Handgrip strength (in $\mathrm{kg}$ ) using a Jamar dynamometer

3. Forced vital capacity

4. MG Quantitative Functional Scale

If patients are on Mestinon, examinations should be done 2 to 6 hours after the last Mestinon dose (in order to assess if the patient is in pharmacologic remission).

At each evaluation, patients will also be asked to complete a MG Quantitative ADL Scale as well as a progress report asking whether the patient subjectively feels they are currently in remission (either on or off medications). 
Based upon the results of the BI's clinical evaluation, each patient will subsequently be assigned an MG grade by the BI (Appendix E). The BI will be responsible for completing all the appropriate case report forms and sending them to the coordinating center of this study for computer entry.

Patients will be routinely followed by the investigator at each center (ie. the "unblinded investigator") between visits by the BI as needed for assessment of medication needs/adjustments and monitoring of immunosuppressive drug side effects. In the event that the unblinded investigator feels that the patient has had a significant relapse, the investigator will complete a "relapse form" (Appendix F) and send it to the coordinating center. A significant relapse will be defined as any symptomatic worsening necessitating a change in medications or a change in MG grade. Other than notification of relapses, only the data obtained during the BI examinations, however, will be utilized for this study.

At the conclusion of the 5 year follow-up evaluation or upon withdrawal from the study, an acetylcholine receptor antibody level will be drawn.

G. End-Points: The primary endpoint for this study will be the number of patients at the end of the follow-up period who are in complete remission off all medications for at least 6 months.

Secondary endpoints will be: 1) the number of patients at the end of the follow-up period who are in pharmacologic remission, 2) MG grade(indicating disease severity) at the end of the study period, 3) average manual muscle test score at the end of the study period, 4)MG quantitative functional score at the end of the study period, 5)MG quantitative ADL score at the end of the study period, 6)average dose of medications. The number of relapses over the study period will also be compared between the two groups.

\section{Monitoring:}

A monitoring committee consisting of 3-4 neurologists and a biostatistician with experience in treating MG patients and clinical trials who are not investigators enrolling patients in the study will review all the case report forms and relapse forms in order to confirm designations of $M G$ grade and criteria for relapse. The committee will meet at a minimum of once a year. In addition, the committee will review the interim statistical analyses.

\section{Sample Size and Statistical Analysis:}

The primary objective of this study is to determine whether thymectomy added to best medical management has an effect on the remission rate. Based upon the published retrospective series previously referenced, we estimate that after 5 years of follow-up, $15 \%$ of patients under best medical management will have achieved complete remission, and $40 \%$ will achieve pharmacologic remission. In order for thymectomy to be considered effective therapy, we will require that the complete and pharmacologic remission rates improve to $30 \%$ and $70 \%$ respectively. The required difference in complete remission rates is equivalent to a hazard ratio of 2.2 , that is, at any point in time, patients undergoing thymectomy are 2.2 times as likely undergo remission. We will require a total of 220 patients (110 in each arm), followed for a minimum of 5 years, in order to detect this difference at the 0.05 level of significance (two-tailed) with $80 \%$ power. Although not the primary focus of the study, this sample size will be more than sufficient to detect the anticipated differences in pharmacologic remissions and will, in fact, allow the inclusion of concomitant variables in the analysis models and the separate analysis of grade or age subgroups, in order to examine the possibility that some types of patients benefit more than others. A study of this size will necessitate the involvement of at least 10 centers, however enrollment would proceed much more quickly with 20 centers. 
Interim analyses will be performed to allow nonthymectomized patients to crossover to the thymcetomy arm as soon as possible if there is clear evidence of a beneficial effect. If 220 patients are accured more or less uniformly over 3 years, and the study is continued until all patients have been followed at least 5 years ( 8 years duration), then, after accounting for the requirement of a 6 month duration of remission, we expect to accrue about 1260 person-years of evaluable follow-up. $25 \%$ of thi experience should be completed by 3.5 years, $50 \%$ will be completed by 5 years and $75 \%$ will be completed by 6.5 years. Interim and final analyses of time to durable remission will be conducted usin! O'Brian-Fleming boundaries (26), at the $\mathrm{p}=0.00004,0.004,0.02$, and 0.041 levels of significance, respectively. This will ensure an overall experiment-wise level of 0.05 .

\section{REFERENCES}

1. Blalock A, Mason MF, Morgan HJ, et al. Myasthenia gravis and tumors of the thymic region. Report of a case in which the tumor was removed. Ann Surg 110:544-561, 1939.

2. Lanska DJ. Indications for thymectomy in myasthenia gravis. Neurology 40:1828-1829, 1990.

3. Rivner M, Swift T. Thymoma: Diagnosis and Management. Seminars in Neurology, Vol.10 No. 1, March 1990.

4. Sommer N, Willcox N, Harcourt CG, Newsom-Davis J. Myasthenic thymus and thymoma are selectively enriched in acetylcholine receptor-reactive T cells. Ann Neurol 28:312-319, 1990.

5. Tindall RSA. Humoral immunity in myasthenia gravis: Effect of steroids and thymectomy. Neurology 30:554-57, 1980.

6. Kornfeld P, Nall J, Smith J, et al. Acetylcholine receptor antibodies in myasthenia gravis. Muscle and Nerve 4: 413-19. 1981.

7. Roses AD, Olanow CW, McAdams MW, Lane RJM. No direct correlation between serum antiacetylcholine receptor antibody levels and the clinical status of individual patients with myasthenia gravis. Neurology 31:220-24. 1981.

8. Seybold ME, Lambert EH, Lennon BA, et al. Experimental autoimmune myasthenia: Clinical, neurophysiologic, and pharmacologic aspects. Ann NY Acad Sci 237:275-282, 1976.

9. Lennon BA, Lindstom JM, Seybold ME: Experimental autoimmune myasthenia gravis: Cellular and humoral immune responses. Ann NY Acad Sci 274:283-299, 1976.

10. Pudifin DJ, Cox J: Lymphocyte subpopulations after thymectomy. Lancet 1:1299, 1976.

11. McQuillen MP, Leone MG. A treatment carol: Thymectomy revisited. Neurology 27:1103-6. 1977

12. Simpson A: An evaluation of thymectomy in myasthenia gravis. Brain 81:112-142, 1958.

13. Mulder DG, Hermann C, Buckberg GD: Effect of thymectomy in patients with myasthenia gravis. Am J Surg 128:202-206, 1974.

14. Emeryk B, Strugalska MH: Evaluation of results of thymectomy in myasthenia gravis. J Neurol 211:155-168, 1976.

15. Perlo VP, Arnason B, Poskanzer D, et al: The role of thymectomy in the treatment of myasthenia gravis. Ann NY Acad Sci 183:308-315, 1971.

16. Papatestas AE, Genkins $G$, Kornfeld $P$, et al: Transcervical thymectomy in myasthenia gravis. Surg Gynecol Obstet 140:535-540, 1975.

17. Kennedy FS, Moersch FP: Myasthenia gravis: Clinical review of 87 cases observed between 1915 and early part of 1932. Can Med Assoc J 37:216-223, 1937.

18. Grob D: Course and management of myasthenia gravis. JAMA 153:529-532, 1953.

19. Oosterhuis HJGH: Studies in myasthenia gravis. Part 1. A clinical study of 180 . J Neurol Sci 1:512-546, 1964. 
20. Osserman KE, Genkins G: Studies in myasthenia gravis: Review of twenty years experience in over 1,200 patients. Mt Sinai J Med NY 38:497-537, 1971.

21. Lavassseur P, Noviant Y, Miranda AR, et al: Thymectomy for myasthenia gravis. $J$ Thorac Cardiovasc Surg 64:1-5, 1972.

22. Simpson JF, Westerberg MR, Magee KR: Myasthenia gravis: An analysis of 295 cases. Acta Neurol Scand, Suppl 23, 42:7-27, 1966.

23. Fujii N, Itoyama Y, Machi M, Goto I. Analysis of prognostic factors in thymectomized patients with myasthenia gravis: correlation between thymic lymphoid cell subsets and postoperative clinical course. J Neurol Sciences 105:143-149, 1991.

24. Beghi E, Antozzi C, Batocchi A, Cornelio F. Prognosis of myasthenia gravis: a multicenter followup study of 844 patients. J. Neurol. Sciences 106:213-220, 1991.

25. Mendell J, Florence J., Manual Muscle Testing. Muscle \& Nerve 13:516-520, 1990.

26. O'Brian PC, Fleming TR. A multiple testing procedure for clinical trials. Biometrics 35:549-556, 1979. 
Principal Investigator

\section{A RANDOMIZED CLINICAL TRIAL OF THYMECTOMY FOR THE TREATMENT OF MYASTHENIA GRAVIS}

\section{MANUAL MUSCLE STRENGTH SCORING FORM}

Center/Patient \#

Patient Initials

Date of Visit_L

Position 1: Sitting

Shoulder abduction $\left(<15^{\circ}\right.$

from horizontal)

Elbow flexion

Wrist flexion

Wrist extension

Thumb abduction

Position 2: Prone

Neck extension

Ankle plantar flexion

Position 3: Side lying

Hip abduction

Position 4: Supine

Elbow extension

Neck flexion

Facial Strength

(eyelid closure)
Right Left
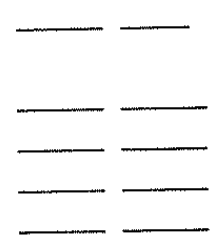

Right Left

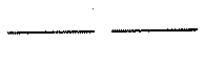

Right Left

Right Left

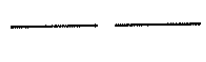

Knee extension (may be $10^{\circ}$ below horizontal Ankle dorsiflexion Ankle eversion Ankle inversion Hip flexion $\left(>30^{\circ}\right.$ from horizontal)

Knee flexion

Hip extension
Right Left

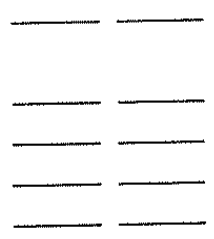

Right Left

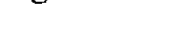

\section{Right Left}

Handgrip dynamometry $(\mathrm{kg})$ :

$$
\begin{aligned}
& \text { RIGHT } \\
& \text { LEFT }
\end{aligned}
$$

Forced vital capacity (liters):

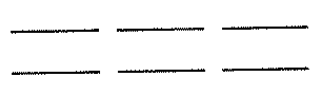

Appendix A 
Principal Investigator

\section{A RANDOMIZED CLINICAL TRIAL OF THYMECTOMY FOR THE TREATMENT OF MYASTHENIA GRAVIS QUANTITATIVE FUNCTIONAL SCORING SYSTEM}

Center/Patient \# Patient Initials

Date of Visit

\begin{tabular}{|c|c|c|c|c|c|}
\hline TEST ITEMS WEAKNESS & NONE & $M I L D$ & MODERATE & SEVERE & $\begin{array}{l}\text { PATIENT } \\
\text { SCORE } \\
\end{array}$ \\
\hline Grade & $\mathbf{0}$ & 1 & 2 & 3 & \\
\hline $\begin{array}{c}\text { Double vision } \\
\text { (lateral gaze) Sec. }\end{array}$ & $>60$ & $>10-60$ & $>1-10$ & $\begin{array}{l}\text { Spontaneous } \\
\text { Heterotropia } \\
\end{array}$ & \\
\hline Ptosis (upward gaze) Sec. & $>60$ & $>10-60$ & $>1-10$ & Spontaneous & \\
\hline $\begin{array}{c}\text { Head, lifted } \\
\left(45^{\circ}, \text { supine }\right) \text { Sec. }\end{array}$ & $>120$ & $>30-120$ & $>0-30$ & 0 & \\
\hline $\begin{array}{l}\text { Right arm outstretched } \\
\left(90^{\circ} \text { standing) Sec. }\right.\end{array}$ & $>240$ & $>90-240$ & $>10-90$ & $\geq 10$ & \\
\hline $\begin{array}{c}\text { Speech following counting } \\
\text { aloud from } 1-100 \\
\text { (onset of dysarthria) } \\
\end{array}$ & $>100$ & $>75-100$ & $>15-74$ & $<25$ & \\
\hline $\begin{array}{l}\text { Right leg outstretched } \\
\left(45^{\circ}, \text { supine }\right) \text { Sec. }\end{array}$ & $>100$ & $>30-100$ & $>0-30$ & 0 & \\
\hline $\begin{array}{c}\text { Vital capacity (l) } \\
\text { male } \\
\text { female }\end{array}$ & $\begin{array}{l}>3.5 \\
>2.5 \\
\end{array}$ & $\begin{array}{l}>2.5-3.5 \\
>1.8-2.5 \\
\end{array}$ & $\begin{array}{l}>1.5-2.5 \\
>1.2-1.8 \\
\end{array}$ & $\begin{array}{l}<1.5 \\
<1.2 \\
\end{array}$ & \\
\hline $\begin{array}{c}\text { Dominant hand grip }(\mathrm{KgW}) \\
\text { male } \\
\text { female }\end{array}$ & $\begin{array}{l}>45 \\
>31\end{array}$ & $\begin{array}{l}>15-45 \\
>10-30 \\
\end{array}$ & $\begin{array}{l}5-15 \\
5-10 \\
\end{array}$ & $\begin{array}{l}<5 \\
<5 \\
\end{array}$ & \\
\hline
\end{tabular}

TOTAL SCORE

Appendix B 
Principal Investigator

\section{A RANDOMIZED CLINICAL TRIAL OF THYMECTOMY FOR THE TREATMENT OF MYASTHENIA GRAVIS}

\section{MYASTHENIA GRAVIS QUANTITATIVE ADL SCORING SYSTEM}

Center/Patient \#

Patient Initials

Date of Visit

\begin{tabular}{|c|c|c|c|c|c|}
\hline GRADE & 0 & 1 & 2 & 3 & $\begin{array}{c}\text { PATIENT } \\
\text { SCORE } \\
\end{array}$ \\
\hline Chewing & Normal & $\begin{array}{c}\text { Fatigue with solid } \\
\text { foods }\end{array}$ & $\begin{array}{l}\text { Fatigue with soft } \\
\text { food }\end{array}$ & $\begin{array}{l}\text { Gastric } \\
\text { tube }\end{array}$ & \\
\hline Swallowing & Normal & $\begin{array}{l}\text { Rare episode of } \\
\text { choking }\end{array}$ & $\begin{array}{l}\text { Frequent choking } \\
\text { necessitating } \\
\text { changes in diet }\end{array}$ & $\begin{array}{l}\text { Gastric } \\
\text { tube }\end{array}$ & \\
\hline Breathing & Normal & $\begin{array}{l}\text { Mild shortness of } \\
\text { breath with exertion }\end{array}$ & $\begin{array}{l}\text { Shortness of } \\
\text { breath at rest }\end{array}$ & $\begin{array}{l}\text { Ventilator } \\
\text { dependence }\end{array}$ & \\
\hline $\begin{array}{l}\text { Impairment of ability } \\
\text { to brush teeth or } \\
\text { comb hair }\end{array}$ & None & Mild & Moderate & Severe & \\
\hline $\begin{array}{l}\text { Impairment of ability } \\
\text { to arise from a chair }\end{array}$ & None & Mild & $\begin{array}{l}\text { Moderate, must } \\
\text { use arms }\end{array}$ & $\begin{array}{c}\text { Severe, } \\
\text { require } \\
\text { assistance } \\
\end{array}$ & \\
\hline $\begin{array}{l}\text { Impairment of ability } \\
\text { to see due to double } \\
\text { vision }\end{array}$ & None & Mild & Moderate & Severe & \\
\hline \multicolumn{5}{|c|}{ TOTAL SCORE } & \\
\hline
\end{tabular}

\section{CONTROLLED STUDY OF THYMECTOMY IN MYASTHENIA GRAVIS MG PATIENT PROGRESS}

1. On the medications you are taking (if any), do you feel that your myasthenia gravis is currently in remission? Yes No

2. If you are not in remission, do you feel your symptoms have improved since your last evaluation? Yes No 
Principal Investigator

\section{A RANDOMIZED CLINICAL TRIAL OF THYMECTOMY FOR THE TREATMENT OF MYASTHENIA GRAVIS}

\section{CLINICAL/LABORATORY DATA SHEET}

Center/Patient\#

Patient Initials

Date of Visit

Results of tensilon test and date performed

Results and date of rep stim (Include recording sites)

Results and date of single fiber (Include muscles tested)

Results and date obtained Acetylcholine Receptor AB assay

Results and date of chest CT

Results and date of anti-striated muscle antibody levels

Patients MG Classification:

Most severe grade Grade at onset of symptoms

Grade at most recent eval

Date

Date

Date

Treatment of MG (briefly state what Rx patient has had and what current meds are)

Appendix D1 
Principal Investigator

\section{A RANDOMIZED CLINICAL TRIAL OF THYMECTOMY FOR THE \\ TREATMENT OF MYASTHENIA GRAVIS}

\section{CLINICAL/LABORATORY DATA SHEET}

Center/Patient \#

Patient Initials

Date of Visit __ 1

\section{DEMOGRAPHIC DATA AND MISTORY}

Date of Birth 1

Ethnic Original: __Caucasian_Black_Hispanic__ Oriental___ Other

\begin{tabular}{|c|c|}
\hline & MONTH \\
\hline stimated onset of symptoms & 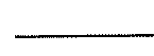 \\
\hline
\end{tabular}

Initial symptoms

Past medical history: __Yes _ No If yes, list below:

1.

3.

4.

Past surgical history: __ Yes __ No If yes, list below:

1.

3.

Allergies: _Yes _ No If yes, list below:

1.

3.

Medications:

1.

3.

4.

2.

4.

2.

4.

2.
.

Appendix D2 
Principal Investigator

\title{
A RANDOMIZED CLINICAL TRIAL OF THYMECTOMY FOR THE TREATMENT OF MYASTHENIA GRAVIS
}

\author{
BLINDED INVESTIGATOR'S PROGRESS ASSESSMENT
}

Center/Patient \#

Patient Initials

Date of Visit

11

1. Patient's current MG classification:

$\begin{array}{ll}\text { Grade 1 } 1- & \text { Grade Oa } \\ \text { Grade 2 } & \text { Grade Ob }- \\ \text { Grade 2B- } & \text { Grade Oc }- \\ \text { Grade 3 } & \text { Grade Oa* } \\ \text { Grade 3B- } & \text { Grade Ob* } \\ \text { Grade 4- } & \text { Grade Oc* } \\ \text { Grade } 4 \mathrm{~B}- & \end{array}$

2. MG quantitative functional score

$(0-24)$

3. MG quantitative ADL score $(0-18)$

4. Average muscle score

(To be calculated by statistical center)

5. Medications patient is currently taking for myasthenia gravis. (Please give doses.)

Mestinon

Prednisone

Imuran

Methotrexate

Cyclophosphamide
Cyclosporine

IVIG

Other 
Principal Investigator

\section{A RANDOMIZED CLINICAL TRIAL OF TUYYMECTOMY FOR THE TREATMENT OF MYASTHENIA GRAVIS}

RELAPSE FORM

Center/Patient \#

Patient Initials

Date of Visit

1. Current MG classification:

2. Previous MG classification:

3. Current MG medication dosages:

Mestinon

Prednisone

Imuran

Methotrexate

4. Previous MG medication dosages:

Mestinon

Prednisone

Imuran

Methotrexate
Cyclophosphamide

Cyclosporine

IVIG

Other

Cyclophosphamide

Cyclosporine

IVIG

Other 
TABLE 1

\section{CLINICAL CLASSIFICATION FOR GRADING MG SEVERITY}

Grade 0 (remission): No symptoms or signs of disease. Patients in clinical remission can include the following groups.

Grade 0a: No objective cranial nerve or extremity weakness. Off all medications.

Grade 0b: No objective cranial nerve or extremity weakness. Remains on Mestinon.

Grade 0c: No objective cranial nerve or extremity weakness. Remains on immunosuppressive drugs.

Grade $0 a+, 0 b+, 0 c+$ : Any of the above 0 stages, but the patient may still have slight orbicularis oculi or hip flexor weakness (grade $4+$ or 5 -), despite the absence of any subjective symptoms of ocular/bulbar or extremity weakness.

Grade 1: Ocular involvement alone (ptosis, diplopia, orbicularis oculi weakness in the absence of other bulbar, neck or limb weakness is allowable in this group).

Grade 2: Mild generalized MG; normal activities of daily living are preserved with only mild symptoms of weakness or fatiguability. Symptoms are mild enough so that they can be managed with Mestinon therapy alone (no immunosuppressive drugs needed). Includes ocular patients with evidence of limb/neck weakness on exam (but no subjective extremity weakness).

Grade 2B: Mild restricted MG; restricted to bulbar involvement without subjective limb weakness (may have subjective/objective neck weakness; the only allowable objective limb weakness would be of the hip flexors, which can be no worse than grade 4; may also have ocular involvement). Symptoms controlled with Mestinon alone; immunosuppressive therapy not required.

Grade 3: Moderate generalized MG; normal activities of daily living are interrupted because of weakness and fatigue to the extent that symptoms require initiation of treatment with immunosuppressive therapy.

Grade 3B: Moderate restricted MG; restricted to bulbar and/or respiratory (diaphragmatic) involvement without subjective limb weakness (may have subjective/objective neck weakness; the only allowable objective limb weakness would be of the hip flexors, which can be no worse than grade 4; may also have ocular involvement); no respiratory failure or inability to swallow requiring mechanical ventilation or feeding. Immunosuppressive therapy is required for treatment.

Grade 4: Severe generalized MG; profound weakness in the extremities requiring confinement to bed and hospitalization; associated with respiratory failure requiring mechanical ventilation or bulbar weakness requiring mechanical feeding (nasogastric or gastric tubes).

Grade 4B: Severe restricted MG; restricted to bulbar and/or respiratory muscles with no subjective limb weakness (may have subjective/objective neck weakness; the only allowable objective limb weakness would be of the hip flexors, which can be no worse than grade 4; may also have ocular involvement); requires mechanical feeding (nasogastric or gastric tubes) or mechanical ventilation. 